\title{
Governance of Poverty Return Under the Background of Big Data
}

\author{
Yang Yuetian ${ }^{1}$, Zheng Yan $^{1, *}$ \\ ${ }^{1}$ Harbin University of Commerce, Harbin, Heilongjiang, 150028, China \\ *Corresponding author. Email: zhengyanyzh1979@163.com
}

\begin{abstract}
The Chinese 14th Five Year Plan period is the key period to consolidate the achievements of poverty alleviation. The Chinese government faces challenge of consolidating the achievements of poverty alleviation and getting rid of the dilemma of poverty return. Based on the multi-disciplinary analysis method, focusing on the problem of poverty return, this paper analyzes big data drive targeted identification objects and causes of poverty return, dynamic supervision and early warning of poverty return. It makes suggestion on big data governance to provide guidance for poverty return, improve quality and efficiency, and consolidate the results of poverty alleviation in the future.
\end{abstract}

Keywords: Poverty alleviation, poverty return, big data, governance

\section{INTRODUCTION}

2020 is a year to decide whether or not success of poverty alleviation in our nation. Its goal and task have been completed as time table. It marks our nation entering into the new era of poverty relief. At the time of completing the goal of poverty relief, we should also clearly realize that some poverty-relief households still have the risk of going poor. The phenomenon of Full to Hungry, Warm to Cold has to be blocked, and policy of Two No-worries and Three Guarantees has to be carried out in sustainable method. Big data plays significant function based on big data, from finding the causes of poverty return, to the dynamic monitoring and forecast warning of the process of poverty relief, from poverty problem to its relief based on big data. The big data application in poverty alleviation provides a strong guarantee for preventing from poverty return during the 14th five year plan period.

\subsection{Achievement of Poverty Alleviation and Phenomenon of Poverty Return}

Poverty relief has been made historic achievements since 18th National Congress of the Communist Party of China. China reached the goal and task of poverty relief over the past eight years as schedule. People and Counties all over the nation are out of poverty and have been taken off the title of poverty based on current poverty standard line. It eliminates absolute poverty and regional overall poverty. Nearly 100 million poor people are out of poverty. It makes great significant victory that the whole world looks at China with new eyes. However, we also are aware clearly that absolute poverty has disappeared but relative poverty still exists even though rural people have sufficient food and living condition and all poverty counties have been taken off the title of poverty. Issue of poverty relief is not end yet, and we have to keep our achievements in poverty relief and prevent from its return. At present, the achievements of poverty alleviation in some areas are not stable; the industrial foundation is still weak, coupled with the impact of Covid-19. Economic income of the people out of poverty is still unstable [1]. At present, nearly 2 million of the people who have been lifted from poverty and nearly 3 million of the marginal population have risk of becoming poor. Its targeted measures should be taken to monitor and assist them timely. We will carry out government policies with requirement of sustainable responsibilities, policies, assistance and supervision after taking off the cap of poverty during the transition period in order to be practical poverty alleviation work, solid process and real effect. Establishing a sound mechanism for avoiding poverty return can consolidate the achievements of poverty alleviation effectively and improve its quality.

Figure 1 is trend of poverty return. QG for poverty line, AC section is beginning of poverty with low living standards. However, with carrying out government poverty relief policy, the people below the poverty line gradually rise their living standards and climb on the poverty line. Its living levels and quality drop by external negative force, majeure factors, their own reasons and etc. when their living standards reach $\mathrm{E}$ point. When trend reaches to $\mathrm{D}$ point, line enters into poverty return [2]. 


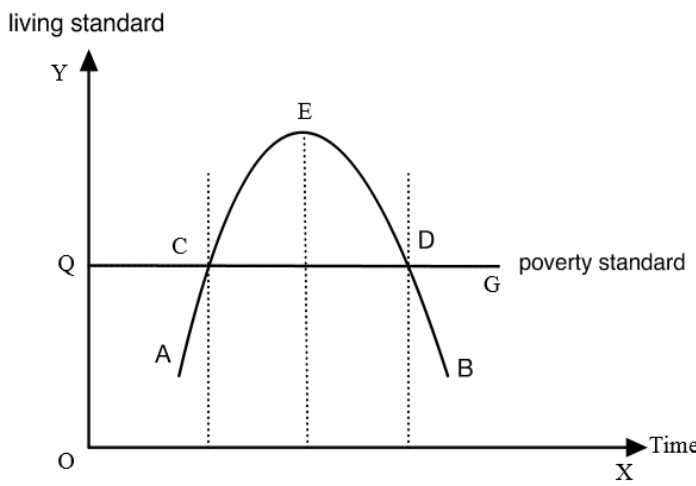

Figure 1 Trend of Poverty return

Technology of big data has become the new application and resources with strategy in the field of poverty governance. The characteristics of big data are high use value, sufficient information, high complexity, fast transmission speed and various roles. As a result, information can be obtained conveniently. Based on Internet, digitization information is already become a significant resource for the government to control poverty relief in a scientific and precise manner.

\section{BIG DATA MECHANISM IN THE ERA OF POST- POVERTY ALLEVIATION}

\subsection{Targeting People of Poverty Return and Their Causes Based on Big Data}

Big data technology can accurately identify causes of poverty. Target groups are identified based on the collected data of poverty alleviation households, age, physical condition, education level, marital status, fertility, family population, work unit, materials of production and living, ways and process of poverty alleviation, taking into account external objective factors such as natural disasters, landform conditions, lack of farmland, skills short and rural communication, poor roads system and etc. The causes of poverty return is analyzed on the big data platform from multiple dimensions and establishes the relationship function between external factors and its phenomenon in order to identify their causes correctly, and provide the basis for reducing poverty return.

Basing on data collection, big data platform can achieve data comparison and comprehensive evaluation, reduce subjective assumptions, analyze the causes of poverty return and their factors leading to poverty return. It can combine people of various poverty categories with the subjective and objective factors of poverty return, evaluate the risk of poverty return, and accurately identify the vulnerability of poverty return. Therefore, it can deeply recover the full scope of details and internal connection that is difficult to present under the traditional sample thinking, deeply excavate the potential regularity behind the complex poverty condition, the quality of poverty relief has to be modified. The mechanism of scientific and targeted poverty return should be established, to guide people of poverty return getting rid of poverty.

\subsection{Big Data Dynamic Monitoring of Poverty Alleviation Achievements}

The big data platform collects data of the people who are at the edge of the poverty line and the poverty-return people, monitors the development process, and implements secondary monitoring. If the out-of-poverty people have the characteristics of poverty return, assistance will come in timely to realize the dynamic mechanism of poverty return, and avoid that people who have been out of poverty occupy social resources in long term and impact assistance of the people of poverty return. The dynamic monitoring of big data enables governance to formulate scientific and reasonable poverty policy according to the latest situation.

\subsection{Efficient Allocation of Poverty Alleviation Resources by Big Data}

Through the observation of the target of poverty alleviation and the analysis of the phenomenon of poverty return, solutions for their reasons are quickly formulated. Taking Zhao'an County, Zhangzhou, Fujian Province as an example, green plum there are oversupply. Covered with the impact of epidemic of Covid-19, its sales channels were narrow and faced a lot of unsalable. At that time, it was found that there were many processing plants in Jieyang, Guangdong Province where the supply of green plum was less than the demand in usual time, and the farmers who grew green plum contacted the production factory in Jieyang as soon as possible to reach cooperation. It achieved efficient allocation of resources.

The big data platform effectively allocates local resources through information collection, supply and demand analysis in order to use of poverty alleviation resources sufficiently and achieve the purpose of precision. It adopts the mode of government + enterprise + cooperative + poor households to help the poor, and provides guidance and help in infrastructure construction, agricultural technology, production material supply, production and sales.

\subsection{Big Data Early Warning Mechanism to Prevent the Emergence of Poverty}

Based on the existing big data platform and monitoring, an early warning system with index is established. It takes timely measures to achieve the early warning and prevention of poverty return when causes of poverty return are predicted. Accuracy of the big data early warning mechanism is decided based on whether or not the data is 
targeted, whether or not database collection is efficient, economic and convenient, and whether or not the database collection content is scientific and reasonable.

The construction of early warning indicators should be able to evaluate comprehensively the status, trend, dimensions and potential risks of the poor. While multi-dimension poverty measurement depends on key relative factors of poverty relief, its governance direction is predicted on the basis of poverty alleviation stability identification and performance. Related indicators are established on the basis of early warning system for poverty alleviation data platform

Poverty alleviation effects of various methods under the same situation are compared and evaluated. It forecasts causes for poverty return based on poverty alleviation risk identification, and constructs multi-level mutual assistance guarantee mechanism for the deficiencies of poverty alleviation, such as guidance of poverty alleviation objects, emergency management of poverty return, prevention of poverty return risk, and joint coordination of government and enterprises. Strategies to alert the emergence of poverty are put forward prevention measures for poverty return (Figure.2)

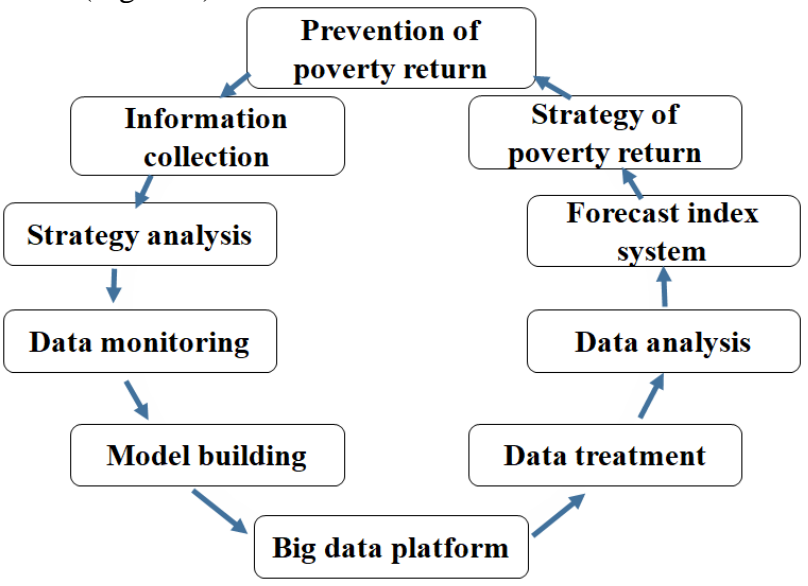

Figure 2 Early Warning Mechanism of Poverty Return

\section{DILEMMA OF POVERTY RETURN GOVERNANCE BASED ON BIG DATA}

\subsection{Big Data Error of Poverty Identification}

The object identification of poverty return governance is not accurate and timely due to the weak Internet use ability and less network behaviour of poverty return population. It has a negative impact on their data collection. Most local governments mainly relied on the filing and card to collect relative data, which led to the data singleness, and may affect its accurate identification and their effectiveness of assistance [3].

The income of rural families is various and it is difficult in the process of investigation and collection. Their income is mainly divided into family operating income and irregular income. When agricultural production planning is carried out by family as a unit, due to existence of many unstable factors such as natural environment and market price, it is hard to calculate accurately their incomes. Irregular income includes migrant workers, private income and government compensation, and then the specific amount is difficult to assess which only the parties themselves know. Human subjective emotions exist in the database process. By the subjective judgment or interest driven of some cadres, some people who should be identified as poverty return are not identified, but the out-of -poverty people who should not be identified. Such identification is inaccurate or even in error. The result is the dislocation of poverty relief management and the waste relative funds, which causes to the inaccuracy of poverty alleviation.

\subsection{Unsmooth Information Channel of Main Poverty Governance Units}

Big data does not form a united force for poverty return in all departments. As to now, the government has not smoothed data share road among its departments. It is hard to mobilize and share data of social and market among agencies for such as education, civil affairs, public security, procuratorial organs and other relevant departments with poverty alleviation departments. At the end, poverty alleviation data were repeated input and proofreading which wastes time and labour. Poverty alleviation identification often lags behind and poverty return does not be blocked timely.

The government lacks of data integration capability and leads to insufficient data sharing of each big data platform. The government is still in the controlling position in the work of poverty alleviation, while the public, private enterprises and the market have not really played their roles there. Some problems include insufficient mobilization and organization, weak policy support and execution, and incomplete mechanism. Effective cooperation mechanism is lack among the main bodies of poverty alleviation, and big data technology cannot effectively play its role among the main bodies.

\subsection{Lack of Personnel Training}

Each step of targeted poverty alleviation needs to be completed by technical talents in the field of its collection, processing, analysis and feedback in the era of big data. But for now, the government does not have sufficient thinking of talented staff for big data, cloud computing and Internet of things technology. At present, it is not clear for the goal of training and shortage of special funds, lead to big data + poverty alleviation practice lack talents of relevant data, cloud computing, Internet of things technology. This causes the lag of poverty alleviation practices with big data. 


\section{SUGGESTIONS FOR POVERTY RELIEF GOVERNANCE IN THE ERA OF BIG DATA}

\subsection{Integrate Data and Break the Data-share Barrier}

An open mechanism for data resource sharing is established, relying on government data platform and service data of various industries, break the restrictions of regions, industries, systems and departments, such as social security, medical care, banks, enterprises and other social service departments, forming a large-scale, multi-dimensional database sharing condition, improving its reliability of data, and optimizing data sharing through cooperation among various departments for poverty standards and content, improving its index system. It provides the foundation for the government to analyze and judge data while it avoids its possible distortion and deviation in the same department [4].

All provinces and cities in China have smooth network platforms and powerful network data processing capabilities in big data system. Especially with the $5 \mathrm{G}$ technology, 5G technology is integrated deeply with services for agriculture in rural areas. At the sixth World Internet Conference held in October 2020. Agriculture Bank of China released the "5G +Scene" smart brand, and it had penetrated into the poor mountainous areas of Hunan Province which has created a new way of network information of poverty relief in the era of big data. Big data platform and Internet+ service platform are increasing deeply and widely and relative data can be penetrated into the areas of finance, education, and government.

\subsection{Training Skills of Government Staff and Poor People on Big Data}

Running of big data platform needs poverty alleviation staff. Lack of data collection staff will make the collected information inaccurate and asymmetric, and reduce the effect of poverty relief. The government should train staff with skill in the field of big data thinking, basic data operation, data management, data update, data decision-making and data output, and integrate data with business. The government should change the traditional empiricism, form a mechanism of clear responsibilities, reasonable decision-making and cooperation, and establish a new system of big data to solid the achievements of poverty relief and prevent poverty return [5].

Actively cultivate and improve the data literacy of poor households. In the rapidly changing era of big data information, the application of big data can help poor households make scientific decisions, improve work efficiency and obtain better labor returns. It is necessary to improve literacy of the poor, ability of using information equipment and network, reading and analyzing network information, and so on. We need the government to guide them to actively obtain new knowledge through various channels, so as to improve their ideological level, learn new ideas, and understand the social trends, and then they can catch up with the step of the times and gradually modify their old ideas. Only in this way can we continue to keep the achievements of poverty relief and prevent poverty return effectively. At present, China has launched the Internet application suitable for aging to use Internet and information equipment, and help them cross the digital divide into the wisdom \& digital era. This requires link among the government, society and families in order to create a good atmosphere for the elderly, guide them to learn actively and strive to adapt to the trend of the times to improve data literacy.

We should also have a look at the differences in knowledge level, age and ideology of the poor, and treat them differently. For those poor people with a certain cultural foundation and strong learning ability, we should give more guidance, provide them with an related environment, and encourage them to get rid of poverty and direct on the road of prosperity by their own efforts. The poor who return to poverty because of their laziness and lack of initiative should be strengthened ideological education, thoroughly change their ideas of equality, dependence and necessity, formulate incentive mechanism, and stimulate their enthusiasm and initiative to become rich.

\subsection{Establishment of the Reliable Big Data System}

We should construct data technology platform, technology of management and application for poverty alleviation matching its goals. Starting from the technical characteristics of social information and big data, we should design the technology platform for data collection, integration and application based on social management and system operation. Combined with its characteristics, it provides a corresponding technical platform for solving its problem with big data.

Building a basic platform for big data, combining the needs of government poverty alleviation and the information of helping objects, we should build a matching data collection path, complete the infrastructure construction such as standardized data sharing, strengthen the integration of data, realize the targeted governance of poverty alleviation through government decision-making model and governance objects, break the original application barriers in data utilization, and build its sharing system [6].

The indicators of data platform are the main basis to reflect condition of poverty return, but the data indicators cannot reflect the degree of poverty accurately. We need to combine its qualitative with its quantitative and to prevent the poverty condition of poor families singly decided by the index score during its evaluation. 


\section{CONCLUSION}

Poverty alleviation is not the end. We have already entered a new era of poverty relief. We should further improve its regulatory targeted mechanism, establish and improve the poverty relief information system based on big data, implement dynamic real-time management, and ensure the healthy operation of poverty relief and its development. The government should promote a series of poverty alleviation information systems, including accurate identification of poverty, accurate decision-making of poverty alleviation projects, accurate management of poverty alleviation process and accurate evaluation of poverty alleviation effect. It should build an information disclosure platform for poverty relief performance evaluation, and promote its evaluation system and poverty alleviation network, establish a sound poverty alleviation network platform, so that poor households can always understand the progress of national poverty alleviation policies, and meet the needs of the poor people's right to know, participate, evaluate and supervise.

\section{ACKNOWLEDGMENT}

Fund Project: Research and Practice of Construction Major in Labor and Social Security from the perspective of Professional Certification (hsdjy202008) under Teaching Reform and Research of Harbin University of Commerce in 2020

\section{REFERENCES}

[1] The Fourth Plenary Session of the 19th Central Committee of the Communist Party of China [M]. Beijing: learning press, 2019, 21. (In Chinese)

[2] CHENG Ming, QIAN Li, WU Bo. Research on the Governance of Poverty Return in the Era of Post Poverty Alleviation [J]. Journal of Chongqing University of Technology (Social Science). 2020(3), 81-87. (In Chinese)

[3] CHADEFAUX T. Early Warning Signals for War in the News [J]. Journal of Peace Research, 2014, (1):5-18.

[4] ZHENG Ruiqiang, CAO Guoqing. Study on Precision Poverty Alleviation Mechanism Based on Big Data Thinking [J]. Guizhou Social Sciences, 2015 (8): 163-168. (In Chinese)

[5] MO Guanghui, ZHANG Yuxue. Innovation Path of Precision Poverty Alleviation Model under the Background of Big Data - series 10th of studies on Performance Improvement Mechanism of Precision
Poverty Alleviation [J]. Theory and Reform, 2017, (1)119-124. (In Chinese)

[6] LIU Ze, CHEN Sheng. Study on the Government Governance Mechanism Driven by Big data - Based on the Analysis of Blocking Poverty Return in the field of Targeted Poverty Alleviation after 2020 [J]. Journal of Chongqing University (SOCIAL SCIENCE EDITION), 2020, (5) 21-229. (In Chinese)

[7] WANG Hao, GU Zhongyang, Du Haitao, etc., Relief Poverty and Taking off the Hat of Poverty is the Starting Point of New Life and New Struggle. General Secretary Xi Jinping's important speech in Shaanxi exited a warm response, [N]. People's Daily, 2020-04-26. (In Chinese) 